\title{
Instalasi Radio Point To Point Mikrotik Tipe Ceragon Fibeair 1500p Dari Cikarang Ke Cimanggis
}

\author{
Dimas Setiaji, ${ }^{1, *}$ Efri Sandy ${ }^{2}$ \\ ${ }^{1}$ Mahasiswa Prodi Pendidikan Teknik Elektronika, Fakultas Teknik -UNJ \\ ${ }^{2}$ Dosen Prodi Pendidikan Teknik Elektronika, Fakultas Teknik -UNJ
}

\begin{abstract}
Abstrak. Perangkat Ceragon FibeAir® IP-MAX2 (G) adalah perangkat radio Point to Point berkapasitas tinggi yang memungkinkan untuk men-deliver data dengan kapasitas besar. Sebuah penyedia jasa jaringan dituntut untuk meningkatkan layanan dalam kualitas suara dan data. Untuk memberikan pelayanan yang semakin baik, maka perlu dioptimalkan layanan yang sudah ada maupun layanan yang akan dibuat. Makalah komprehensif ini bertujuan untuk mengintalasi radio point to point mikrotik tipe Ceragon FibeAir 1500P untuk membackup jaringan dan meningkatkan kualitas layanan data di PT. Citra Sari Makmur. Dalam menginstal radio point to point harus sesuai dengan tahapan dan memperhatikan frekuensi kerja agar dapat mempertimbangkan noise dan daya yang diterima serta melakukan pointing antenna supaya parameter yang didapat sesuai dengan yang diinginkan.
\end{abstract}

\section{Kata Kunci : Ceragon FibeAir 1500P, Point to point, Mikrotik}

\begin{abstract}
Ceragon FibeAir® IP-MAX2 (G) device is a high capacity Point to Point radio device that enables large capacity data delivery. A network service provider is required to improve services in voice and data quality. To provide better service, it is necessary to optimize existing services and services that will be made. This comprehensive paper aims to install a radio point to point microtic type Ceragon FibeAir 1500P to back up the network and improve the quality of data services at PT. Citra Sari Makmur. In installing a point to point radio, it must be in accordance with the stages and pay attention to the working frequency in order to consider the noise and power received and do the pointing of the antenna so that the parameters obtained are as desired.
\end{abstract}

Keywords: Ceragon FibeAir 1500P, Point to point, Mikrotik

\section{Pendahuluan}

Menurut Deloitte Technology Fast 2012 perkembangan dunia telekomunikasi sangat pesat dan begitu banyak memberikan berbagai kemudahan dan kenyamanan dalam berkomunikasi. Perkembangan teknologi informasi tidak bisa dipisahkan dari perkembangan teknologi dan infrastruktur jaringan komputer. Contoh paling mudahnya adalah menjamurnya media sosial yang tidak bisa dipungkiri memiliki andil besar terhadap cepatnya informasi terkirim dari pusat informasi sampai ke penerima informasi. Kita bisa dengan mudah mendapatkan informasi, bahkan melalui media ponsel sekalipun, hal ini dikarenakan semakin maraknya penggunaan jaringan komputer. Oleh karena itu diperlukan infrastruktur yang mampu memenuhi kebutuhan pengiriman data dengan cepat dan mudah diakses..

Jaringan point to point merupakan jaringan yang dilakukan secara langsung antar dua komputer (node). Adapun beberapa kelebihannya yakni dapat mengatasi kendala komunikasi dan mengirimkan sinyal secara efektif serta dapat dipergunakan pada berbagai macam ligkungan, seperti diatas gedung, diatas tower, dan diatas bukit.

PT. Citra Sari Makmur (CSM) sebagai salah satu penyedia jasa jaringan di Indonesia dituntut untuk meningkatkan layanan dalam kualitas suara dan data. Untuk memberikan pelayanan yang semakin baik, maka perlu dioptimalkan layanan yang sudah ada maupun layanan yang akan dibuat.

Sistem komunikasi radio pada saat ini telah mulai banyak dipakai dan telah berkembang aplikasinya. Hal ini dikarenakan fungsi radio sebagai salah satu media transmisi komunikasi yang mempunyai beberapa keunggulan dibandingkan media trannsmisi lain seperti kabel dan serat optik. Keunggulan itu diantaranya biaya instalasi yang mudah dan murah, area cakupan yang luas serta pembangunannya yang dapat dicicil.

Pada awalanya PT. Citra Sari Makmur (CSM) menggunakan fiber optik sebagai media transmisi data dan penghubung jaringan di wilayah Jakarta ke server pusat di Cikarang. Seiring banyaknya pembangunan infrastruktur di wilayah Jakarta menyebabkan sering terjadi gangguan pada kabel optik yang mengakibatkan terputusnya jaringan. Untuk mengatasi hal tersebut, maka diperlukan perangkat radio point to point mikrotik tipe CERAGON FIBEAIR 1500P dari cikarang ke cimanggis untuk membackup jaringan apabila terjadi gangguan. Diharapkan dengan penelitian ini dapat meningkatkan pelayanan jasa jaringan telekomunikasi tersebut.

*Corresponding author: dimassetiaji.unj@gmail.com 


\section{Metodologi}

\subsection{Jaringan Point To Point (PTP)}

Jaringan point to point merupakan jaringan komunikasi yang terdiri dari 2 titik yang terhubung melalui link permanen, baik menggunakan media wireline ataupun wireless. Pada jaringan ini juga memiliki keleluasaan dalam komunikasi. Dalam pemanfaatannya, jaringan point to point banyak digunakan sebagai WLAN, backbone, serta jaringan akses kecepatan tinggi.

\subsection{Mikrotik}

Routerboard /mirotik sering sekali kita temui dengan beberapa tipe yaitu RB750, RB750GL, RB433, RB411, dan lain-lain. Digit pada tipe itu adalah indikator spesifikasi dari tipe routerboard itu sendiri. populer digunakan saat ini adalah Mikrotik RouterOS. Mikrotik RouterOS, merupakan sistem operasi Linux base yang diperuntukkan sebagai network router. Didesain untuk memberikan kemudahan bagi penggunanya. Administrasinya bisa dilakukan melalui Windows Application (WinBox). Selain itu instalasi dapat dilakukan pada Standard komputer PC (Personal Computer). PC yang akan dijadikan router mikrotik pun tidak memerlukan resource yang cukup besar untuk penggunaan standard, misalnya hanya sebagai gateway. Untuk keperluan beban yang besar (network yang kompleks, routing yang rumit) disarankan untuk mempertimbangkan pemilihan resource PC yang memadai

Router Mikrotik bisa digunakan pada jaringan komputer berskala kecil atau besar, hal ini tentunya disesuaikan pada resource daripada komputer itu sendiri. Jika mikrotik digunakan untuk mengatur network kecil maka penggunaan perangkat komputernya bisa yang biasa-biasa saja, namun jika yang ditanganinya adalah jaringan berskala besar seperti kelas ISP maka penggunaan perangkat komputernya pun harus yang benar-benar handal yang memiliki spesifikasi tinggi.

\subsection{Antenna}

Antena adalah sebuah komponen yang dirancang untuk bisa memancarkan dan atau menerima gelombang elektomagnetika (Mudrik Alaydrus, 2011:1). Antena sebagai alat pemancar (transmitting antenna) adalah sebuah transducer (pengubah) elektromagnetis, yang digunakan untuk mengubah gelombang tertuntun di dalam saluran transmisi kabel, menjadi gelombang yang merambat di ruang bebas, dan sebagai alat penerima (receiving antenna) mengubah gelombang ruang bebas menjadi gelombang tertuntun. Antena juga dapat didefinisikan juga sebagai elemen konduktor yang merubah atau mendeteksi perubahan gelombang elektromagnetik dengan efisien. Antena adalah elemen penting yang ada pada setiap sistem telekomunikasi tanpa kabel (nikabel/wireless), tidak ada sistem telekomunikasi wireless yang tidak memiliki antena. Pemilihan antena yang tepat, perancanagan yang baik dan pemasangan yang benar akan menjamin kinerja (perfomansi) sistem tersebut.

Antena memiliki beberapa Karakteristik penting dalam mendukung kinerjanya. Karakteristik atau parameter kinerja ini perlu diperhatikan saat membuat atau memilih jenis antenna yang akan digunakan. Ada beberapa karakteristik atau parameter penting antena yang perlu dipertimbangkan dalam memilih jenis antena untuk suatu aplikasi, yaitu pola radiasi, direktivitas, gain dan polarisasi. Karakter - karakter ini umumnya sama pada sebuah antena, baik ketikaantena tersebut menjadi peradiasi atau menjadi penerima untuk suatu frekuensi.

\subsection{Ceragon FibeAir ${ }^{\circledR}$ IP-MAX2 (G)}

Perangkat Ceragon FibeAirß IP-MAX2 (G) adalah perangkat radio Point to Point berkapasitas tinggi yang memungkinkan untuk men-deliver data dengan kapasitas besar. Salah satu tipe radio dari perangkat kelas ini adalah Ceragon FibeAir 1500P. Ceragon FibeAir 1500P terdiri dari 2 bagian, yaitu Indoor Unit dan Outdoor Unit.

\subsection{Diagram Blok}




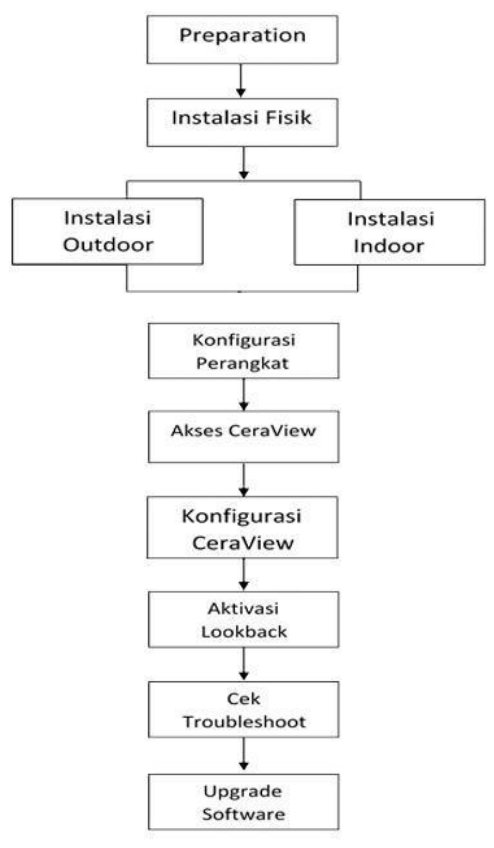

Gambar 1. Langkah-Langkah Instalasi

\section{Hasil Penelitian}

\subsection{Persiapan}

Sebelum memulai proses instalasi, sebaiknya periksa dahulu keseluruhan perangkat Ceragon seperti IDU, ODU / RFU, pole mount kit dan Coupler Holder, Antena, Arrester untuk proteksi perangkat, kabel (Waveguide dan Coax Cable) dan konektor serta mounting untuk dudukan antena dan bracket / pole mount kit ODU. Pastikan perangkat yang akan dipasang di sisi lokal (site A) adalah perangkat dengan tipe yang sesuai dengan perangkat yang akan dipasang di sisi remote (site B). Selain itu juga persiapkan installation kit seperti rubber tape, asphalt, silicon gel, tie wrap, sekun, cagenut dan baut.

Untuk membantu pekerjaan instalasi juga dibutuhkan perkakas/tool yang meliputi standar tool seperti kunci Inggris, kunci L, obeng, tang potong, cutter, teropong, tang sekun, multitester, safety belt, katrol dan tambang. Selain itu kita juga membutuhkan GPS (garmin atau magellan), altimeter dan kompas (sunto) untuk membantu memudahkan kita mengenal koordinat, mengetahui besarnya kecepatan angin dan arah mata angin. Kemudian untuk melakukan setting konfigurasi perangkat dibutuhkan cabling yaitu cross-over cable, straight- through cable dan console cable.

\subsection{Instalasi Indoor}

Instalasi Indoor Unit Ceragon sangat mudah dilakukan. Perangkat IDU hanya membutuhkan space 1U di rack sehingga sangat memudahkan proses instalasi. Dibutuhkan 4 cage nut untuk melekatkan plat kupingan IDU ke rack. Sedangkan kabel power

DC juga sudah disediakan dari Ceragon dan petunjuk instalasinya sudah jelas terlihat di warna kabel dan tanda plus (+), minus (-) maupun ground. Seperti sudah dijelaskan di bab sebelumnya, bahwa DC Supply Ceragon dilengkapi dengan Reverse Voltage sehingga apabila terjadi kesalahan pemasangan kabel power di MCB rectifier, tidak akan menyebabkan perangkat rusak. Apabila semua sudah terkoneksi dan terkonfigur dengan benar, maka semua LED yang ada di front display IDU akan menyala hijau seperti terlihat pada Gambar 2.

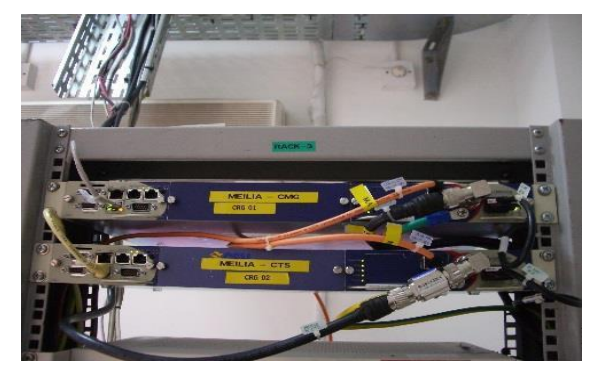

Gambar 2. IDU Ceragon installed 
Sebaliknya apabila ada parameter yang belum terkonfigur atau terinstal dengan benar maka akan ada alarm merah.

\subsection{Instalasi Outdoor}

Instalasi Outdoor merupakan tahapan yang amat penting dan paling susah pengerjaannya. Dimulai dari merakit mounting antena, menaikkan antena ke tower, memasang RFU dan mengkoneksikan kabel dan konektor. Dalam subbab kali ini hanya akan dibahas mengenai instalasi Remote Mount 1+0. Sedangkan untuk instalasi antena dan mounting serta pemasangan konektor $\mathrm{N}$ - male pada IF coax cable tidak akan dibahas karena metodenya secara keseluruhan sama dengan produk selain Ceragon.

Beberapa langkah untuk instalasi Fibe Air 1500P dengan konfigurasi remote mount 1+0 adalah sebagai berikut :

1) Pasang Pole Mount Kit pada pole mounting antena menggunakan 4 baut dan mur seperti pada Gambar 3.

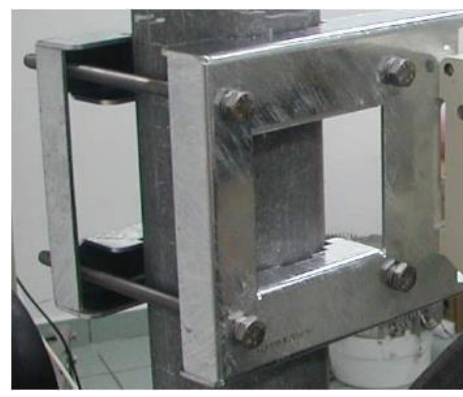

Gambar 3. Pole Mount Kit terpasang pada Pole Mounting Antena

2) Pasang Coupler Holder di Pole Mount Kit terlihat pada Gambar 4.

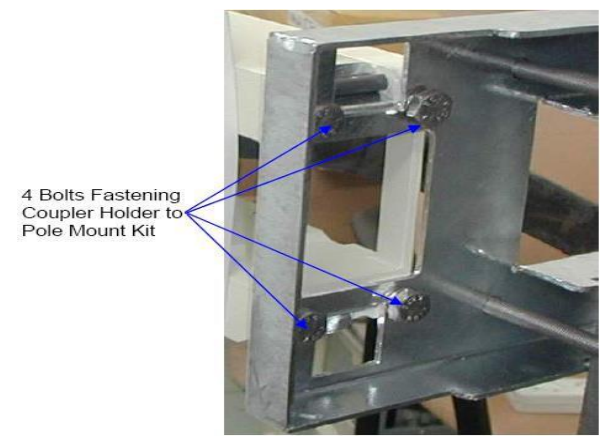

Gambar 4. Coupler Holder terpasang pada Pole Mount Kit

3) Masukkan O-Ring pada alurnya di RFU/ODU, pasang O-Ring unit ke RFU dan kencangkan dengan menggunakan 4 allen screws. Gambar

2.2. merupakan contoh O-Ring dan Gambar 5. O-Ring yang telah terpasang.

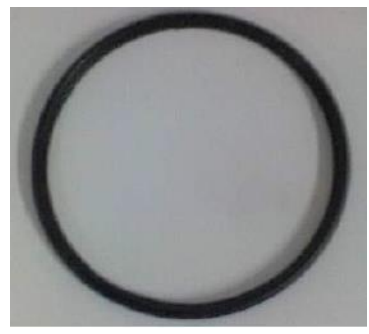

Gambar 5. O-Ring Unit 


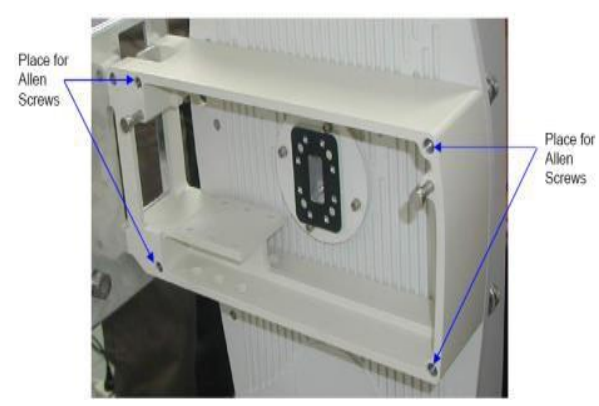

Gambar 6. O-Ring Unit terpasang pada RFU

3) Oleskan silicon gel pada alur O-Ring untuk mencegah masuknya air atau zat-zat lain ke dalam RFU.

4) Pasang RFU ke Coupler Holder menggunakan 4 allen screws

5) Pasang Waveguide ke RFU waveguide interface menggunakan 8 allen screws terlihat pada Gambar 7.

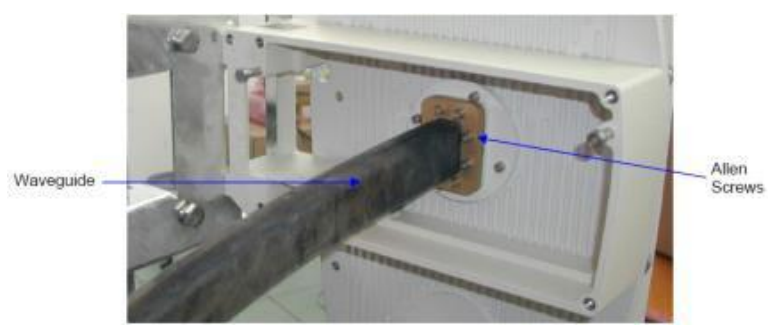

Gambar 7. Waveguide terpasang pada RFU

6) Complete Installation 1+0 terlihat pada Gambar 7

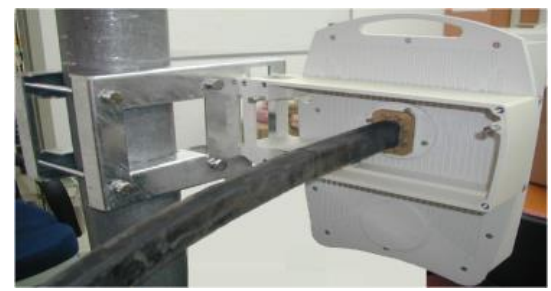

Gambar 7. Instalasi Selesai

\subsection{Setting Konfigurasi Perangkat}

Setting Konfigurasi yang dimaksud disini adalah hanya untuk initial setup assign IP address di IDU. Untuk melakukannya bisa dilakukan melalui Hyper Terminal atau telnet ke perangkat apabila sudah mengetahui IP dari IDU.

Langkah-langkah initial setup menggunakan Craft Terminal adalah sebagai berikut :

1) Nyalakan IDU

2) Pasang kabel console serial RS-232 ke port Terminal di IDC dan koneksikan dengan PC atau Laptop

3) Pilih Start $\rightarrow$ Programs $\rightarrow$ Accessories $\rightarrow$ Communication $\rightarrow$ Hyper Terminal

4) Double Click Hyper Terminal icon

5) Ketik "sembarang" untuk Connection Description dan klik ok

6) Pada kolom Connect Using, pilih com properties kita yang terkoneksi dengan Terminal IDU Ceragon

7) Pada tab Port Settings ikuti setting dibawah :
a. Bits per second - 19200
b. Data bits -8
c. Parity - None 
8) Klik OK

d. Stop bits -1

e. Flow Control - Hardware

9) Setelah Connect ke Terminal, untuk masuk ke setup program, tekan Enter sekali.

10) Password : Ceragon

Selanjutnya untuk mendefinisikan IP Address ikuti langkah dibawah :

1) Pada main terminal program menu terlihat pada Gambar 8., pilih Configuration

2) Pilih IDC

3) Pilih Basic

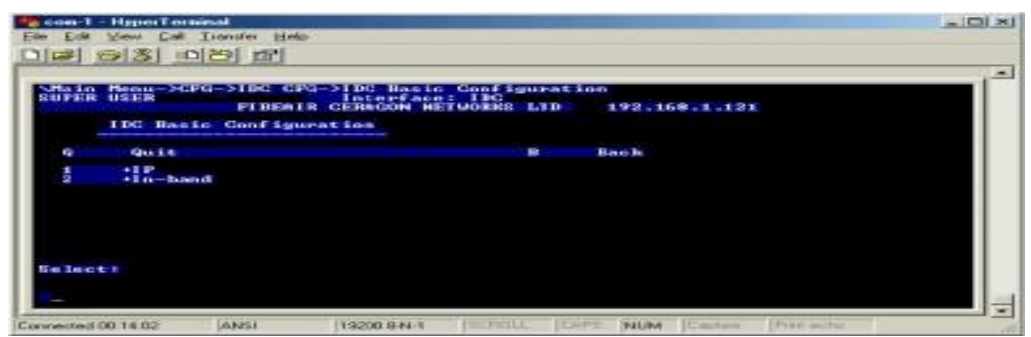

Gambar 8. Hyper Terminal Menu

4) Pilih IP dan masukkan IP address yang baru

5) Pilih Save dan restart sistem, sebelum sistem restart perangkat akan tetap membaca IP yang lama.

\subsection{CeraView}

CeraView adalah sebuah software management yang berfungsi untuk melakukan konfigurasi dan monitor jaringan Radio Ceragon. CeraView bisa diinstal di PC atau Laptop dengan Operating System berbasis Windows maupun Linux. Semua setting konfigurasi dan parameter perangkat bisa dilakukan dari CeraView kecuali assign IP address yang baru yang hanya bisa dilakukan dari Hyper Terminal atau Telnet seperti yang telah dijelaskan di bab sebelumnya.

\subsection{Akses CeraView}

Sebagai catatan, untuk PC dengan OS berbasis Windows 2000/2003/XP, user yang akan mengakses CeraView harus bertindak sebagai Administrator.

Langkah - langkah untuk masuk ke CeraView sebagai berikut :

1) Klik Start $\rightarrow$ Programs $\rightarrow$ CeraView $\rightarrow$ CeraView Element Manager

Login Windows akan tampak seperti Gambar 9.

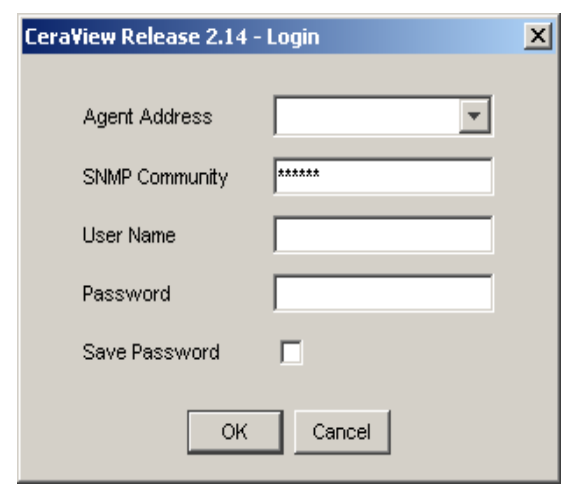

Gambar 9. CeraView Login Window

\subsection{Konfigurasi CeraView}

Setelah instalasi fisik selesai dikerjakan baik indoor maupun outdoor, hal selanjutnya yang akan dilakukan adalah memastikan sistem bekerja dengan baik. Untuk itu langkah pertama adalah menyalakan radio. Setelah sistem booting selesai, langkah pertama adalah meng-assign IP address perangkat sesuai dengan IP yang diinginkan. Untuk inisialisai awal, pilih File $\rightarrow$ System $\rightarrow$ Information dan akan tampak setting parameter.

Isikan informasi yang diperlukan mengenai Deskripsi, Name, Contact dan Location. Yang penting lagi 
adalah setting Waktu dengan cara klik Date/Time Configuration dan update setting waktu sesuai dengan waktu server atau Laptop. Hal ini berfungsi untuk mengetahui waktu apabila terjadi alarm, indikasi problem atau hal-hal lain sesuai dengan waktu yang telah ditetapkan.

Langkah selanjutnya adalah setting parameter frekuensi radio. Seperti telah dibahas sebelumnya, radio Ceragon merupakan sistem radio Point to Point yang masing-masing tipe RFU-nya mempunyai 4 band/channel frekuensi yang saling berpasangan (tipe TL/Transmit Low dan tipe TH/Transmit High). Untuk setting frekuensi pilih Configuration $\rightarrow$ RFU

$\rightarrow$ Right $\rightarrow$ RFU Configuration dan akan tampak Gambar 10. dibawah.

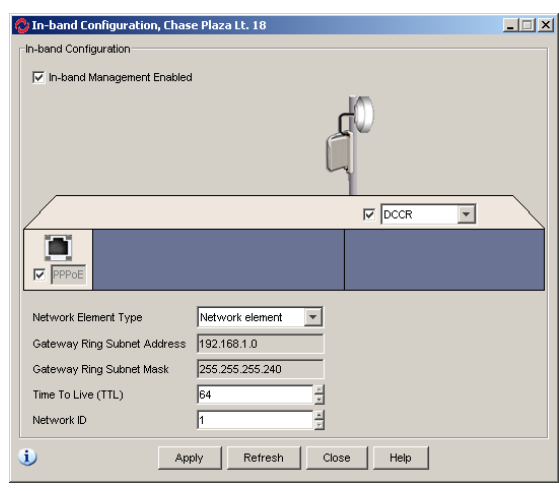

Gambar 10. Setting Frekuensi dan Transmit Power

Untuk awal instalasi, isi Tx Frequency dan Rx Frequency secara manual agar Tx Channel dapat berfungsi. Set Transmit Power (Set Tx Level) sesuai dengan input range $(10-24 \mathrm{dBm})$ agar RSL/Radio Signal Level (Monitored Rx Level) yang didapat sesuai dengan Link Budget Pathloss yang telah dibuat. Untuk link dengan jarak yang tidak terlalu jauh $(<5 \mathrm{~km}$ ) dengan menggunakan antena $0.6 \mathrm{~m}$, bisa juga diaktifkan fungsi ATPC (Automatic Transmit Power Control) dengan cara memberi centang pada kotak kecil disamping ATPC. ATPC adalah feature yang berfungsi untuk mengontrol Transmit Power radio sesuai dengan RSL yang diinginkan (Set reference Rx Level), ini bertujuan untuk memperpanjang Lifetime perangkat dan meminimalisir terjadinya self interference dengan radio lain yang bekerja pada frekuensi yang berdekatan. Setelah semua parameter diisi, klik Apply kemudian klik Refresh.

\section{Kesimpulan}

Pada makalah komprehensif ini, dilakukan instalasi radio point to point mikrotik tipe Ceragon FibeAir 1500P dari cikarang ke cimanggis. Maka didapatkan kesimpulan sebagai berikut Dalam jaringan radio point to point tidak boleh terhalang oleh apapun agar sinyal yang diterima menjadi lebih baik. Pada pemilihan frekuensi kerja, ada beberapa faktor yang harus dipertimbangkan diantaranya noise dan daya yang diterima. Pointing antenna dilakukan agar nilai parameter yang didapat seperti noise dan daya yang diterima sesuai dengan yang diinginkan

\section{Daftar Pustaka}

1. Amalia, Rahma. 2016. “Analisa Kinerja Radio Point To Point Mikrotik Tipe-433 Dalam Keadaan Interferensi”. Skripsi. Universitas Negeri Jakarta.

2. Fakultas Teknik. 2016. "Buku Pedoman Skripsi/Karya Inovatif/Komprehensif”. Jakarta: Fakultas Teknik, Universitas Negeri Jakarta.

3. H.Morais, Douglass. 2004. Fixed Broadband Wireless Communication. San Mateo : Pearson Education .

4. Rambe, Ahmad Mulia. 2003. "Penggunaan Serat Optik Plastik Sebagai Media Transmisi Untuk Alat Ukur Temperatur Jarak Jauh”. Skripsi. Universitas Sumatera Utara.

5. Santosos, Gempur. 2005. “Metodologi Penelitian Kuantitatif dan Kualitatif”. Surabaya

: Prestasi Pustaka Publisher.

6. Setiabudi, Darmawan. 2011. "Perencanaan Link Transmisi Radio Paket Microwave Perangkat Cewagon FibeAir 1528HP Untuk PT Telkom, TBK Area Riau Daratan dan Riau Kepulauan”. Skripsi. Universitas Telkom.

7. Stalling, W. 2007. Komunikasi Dan Jaringan Nirkabel. Yogyakarta: Andi 